\title{
Abordagem Artística do Trauma de Guerra no Teatro Polonês na Segunda Metade do Século XX: o exemplo do espetáculo Akrópolis do Teatro Laboratório das 13 Fileiras encenado por Jerzy Grotowski
}

\author{
Juliusz Tyszka ${ }^{1}$ \\ Universidade Adam Mickiewicz - Poznań, Polônia \\ E-mail: osty@wp.pl \\ Tradução: Ana Cristine Wegner \\ E-mail: ana_wegner@yahoo.fr
}

Resumo

O presente artigo discorre sobre o teatro polonês pós segunda guerra mundial, trazendo como exemplo o espetáculo Akrópolis encenado por Jerzy Grotowski com influência direta do regime nazista para sua concepção. Embasando historicamente a situação da Polônia nesses períodos entre guerras, o artigo estabelece uma reflexão sobre as perdas e os traumas que uma guerra pode causar em um país e no seu panorama artístico-teatral.
This article discusses Polish theater after the Second World War, using by example the play Akrópolis staged by Jerzy Grotowski with direct influence of the Nazi regime for its conception. Historically basing the situation of Poland in these periods between wars, the article establishes a reflection on the losses and traumas that a war can cause in a country and in its artistic-theatrical panorama. 
É impossível abordar a questão do trauma de guerra no teatro contemporâneo polonês sem lembrar - ainda que rapidamente - o impacto forte e doloroso que as insurreições e as guerras dos séculos XIX e XX tiveram sobre a história de meu país e sobre a sensibilidade polonesa. Comecemos por citar o fato de que a Polônia, sendo ainda em meados do século XVII um dos maiores e mais influentes países da Europa, perdeu sua independência em 1794. Seu território foi dividido entre três países: a Áustria, a Prússia e a Rússia. Tal configuração durou até o final da Primeira Guerra Mundial sendo que as insurreições contra o invasor russo (1830-1831 e 1863-1864) e contra os invasores germânicos (1848) resultaram somente em fracassos e no aumento de represálias.

Dezenas de milhares de pessoas pereceram, morrendo como soldados, resistentes ou vítimas de repressões, dezenas de milhares de indivíduos foram deportados para a Sibéria, e uma parcela da população se "russificou" ou se "germanizou". Os poloneses sofreram o destino das minorias étnicas das fronteiras dos impérios europeus, cujos dirigentes visavam a unificação cultural e linguística de seus cidadãos - como aconteceu em outras nações vizinhas. Um sistema de censura estava em vigor em terras ocupadas pela Prússia e pela Rússia, cujos serviços secretos ostentavam sua eficácia, e toda e qualquer alusão à Polônia livre implicava punições severas. Nos períodos mais virulentos das repressões - sob as ocupações russa e prussiana - os únicos espaços públicos onde era autorizada a elocução em língua polonesa eram as igrejas e os teatros. O trauma da guerra renascia depois de cada insurreição derrotada, reforçado ainda pelas represálias dos invasores.

A língua e a cultura polonesa devem suas sobrevivências ao engajamento cívico de milhares de heróis anônimos cujo acirrado trabalho cotidiano contribuía à preservação da identidade nacional. Seus esforços eram apoiados por padres da igreja católica. As obras de grandes artistas, especialmente os poetas românticos Adam Mickiewicz, Juliusz

1 Diretor do Laboratório de Estudos Performáticos, Instituto de Estudos Culturais, Faculdade de Ciências Sociais.
Slowacki, Zygmunt Krasiński (considerados na Polônia como visionários ou bardos nacionais), foram igualmente de grande importância. Seus escritos não censurados, redigidos e impressos fora do território polonês (principalmente na França), e enviados clandestinamente à Polônia ocupada, atiçavam o espírito de resistência e influenciavam o pensamento político polonês. É necessário acrescentar que as obras dos bardos nacionais, sobretudo as de Slowacki, eram dotadas de um forte espírito crítico, no que diz respeito a seus conterrâneos. Os grandes poetas românticos descreviam a índole nacional polonesa com uma certa ironia amarga para que os poloneses não se esquecessem que a perda da independência do país não se devia somente ao curso dos eventos inevitáveis e aos atos dos potentes impérios vizinhos, ela era também o fruto do orgulho, da indolência, da negligência, da embriaguez, dos erros políticos de muitas gerações polonesas e, enfim, da traição.

A Primeira Guerra Mundial não ficou na memória dos poloneses e polonesas como um evento particularmente trágico. Seu traumatismo foi ofuscado pela independência proclamada no dia do final da guerra, em 11 de novembro de 1918. A destruição selvagem do centro da cidade de Kalisz pelo exército prussiano, adicionado aos assassinatos e estupros da população civil (de 7 a 22 de agosto de 1914), e o fato da guerra ter oposto pessoas próximas e parentes, separados pelas fronteiras entre os ocupantes e os incorporados aos seus exércitos, são as únicas circunstâncias trágicas guardadas em nossa memória coletiva.

Depois da Independência, a paz não durou muito tempo: em fevereiro de 1919, as tropas polonesas recém-formadas afrontaram o exército bolchevique, avançando em direção da fronteira prussiana com o objetivo de propagar a revolução proletária no Ocidente. A guerra polonesa-soviética durou um ano e meio, devastando a costa leste do país, que recém acabara de se reconstruir, e custando a vida de dezenas de milhares de soldados e civis. Na Polônia, recorda-se sobretudo dos atos de extrema crueldade dos soldados soviéticos do primeiro Regimento de Cavalaria de Semion Boudienny, ou seja, o massacre 
dos prisioneiros da guarnição em Żytomierz e o incêndio de um hospital em Berdyczów, com pacientes e o corpo clínico dentro (os dois crimes foram cometidos no dia 7 de agosto de 1920). O tratado de paz que finalmente estipulava a fronteira polonesa-soviética foi firmado em Riga (Letônia), em 18 de março de 1921.

A paz durou dezoito anos: dia $1^{\circ}$ de setembro de 1939, as tropas de Hitler invadiram o oeste, o norte e o sul da Polônia, dando início assim à Segunda Guerra Mundial. Enquanto os alemães se aproximavam de Varsóvia, no dia 17 de setembro, as tropas da União das Repúblicas Socialistas Soviéticas (URSS) atacaram o leste da Polônia. A derrota do exército polonês se deu por volta do final do mês de setembro, quando o país se rendeu e os invasores o dividiram em duas zonas: uma alemã e outra soviética, concretizando o protocolo secreto do Pacto Molotov-Ribbentrop, firmado em Moscou, em 23 de agosto de 1939. O governo polonês foi exilado à Romênia e mais tarde à França. Depois da derrota francesa, em 1940, a sede do governo polonês foi então transferida para Londres até o final da guerra.

Os historiadores costumam comparar a situação da Polônia e dos poloneses durante a Segunda Guerra Mundial com a de um herói da tragédia grega: o governo polonês estava em exílio, os líderes da resistência ficaram no país e cabia aos cidadãos escolher qual dos dois males era o menor. Nosso país foi a proa dos mais cruéis totalitarismos do século XX (o hitlerismo e o stalinismo) sem receber algum apoio de seus próprios aliados - a França e a Inglaterra, e depois os Estados Unidos da América e a Inglaterra. Estes buscavam primeiramente repelir a expansão alemã em direção ao leste, para não mais precisar afrontá-la em seus territórios, entregando a Polônia ao seu outro aliado - a URSS, que visava dominar toda a Europa central.

De modo concomitante, os ocupantes nazistas e stalinistas prosseguiam, cada um à sua maneira, seus objetivos criminosos e inescrupulosos. O objetivo dos nazistas consistia primeiramente em exterminar os cidadãos poloneses de origem judia e em seguida eliminar uma vasta parcela da nação polonesa, sobretudo suas elites. O número final de poloneses e polonesas se limitaria, assim, a alguns milhões. E, portanto, se esperava executar mais de vinte milhões de pessoas de nacionalidade polonesa - uma vez que esse objetivo alcançado, a "questão polonesa" estaria resolvida: bastaria expatriar os poloneses em territórios ocupados da Rússia, onde eles se tornariam escravos ao serviço da "casta dos senhores" e executariam trabalhos simples em prol dos "super-homens" germânicos, como todos os "sub-homens" eslavos.

O ocupante stalinista, por sua vez, pretendia incorporar a Polônia à União Soviética e, portanto, submeter os poloneses a um processo de "russificação". Os objetivos oficiais, apoiados pela ideologia comunista, foram assim copiados do imperialismo russo, bem conhecido na Polônia por causa da ocupação do século XIX.

As duas potências totalitárias decidiram exterminar as elites polonesas. Os alemães começaram a atingir seu objetivo durante a Blitzkrieg ${ }^{2}$ de setembro de 1939: depois de ocupar cidades e vilarejos poloneses, eles fuzilavam imediatamente, sem julgamento, os homens políticos, militantes, médicos, juristas e professores locais. A prisão de cento e sessenta e nove professores da Universidade Jagiellonian e de outras escolas superiores da Cracóvia, em 6 de novembro de 1939, e suas respetivas deportações para o campo de concentração de Sachsenhausen, causaram um efeito retumbante. Eles foram recebidos pelo Comandante Rudolf Hœss (futuro comandante do campo de Auschwitz) gritando: "Vocês são todos umas merdas do Reich Pan-Alemão. O campo de concentração é apenas um monte de porcaria onde todos vocês vão apodrecer. O único caminho à liberdade para vocês é a chaminé do crematório"3.

Já o maior crime do regime stalinista foi o massacre de vinte e dois mil oficiais poloneses e

2 N. T.: Tática militar que consiste em realizar ataques relâmpago e surpresa, no intuito de evitar que os inimigos tenham tempo de organizar sua defesa.

3 Disponível em: http://kalendarium.polska.pl/wydarzenia/article.htm?id=37442. Acesso em: 12 mar. 2010. 
oficiais subalternos do exército polonês em Katyń (Bielo-Rússia soviética) em abril de 1940, que haviam sido presos em setembro de 1939.

Somente após a contagem do número de vítimas, uma vez findada a guerra, foi possível tomar consciência da dimensão da catástrofe. A Polônia, no Período Entreguerras, contabilizava cerca de trinta milhões de cidadãos, após a Segunda Guerra Mundial apenas vinte dois milhões e meio permaneceram. Os nazistas exterminaram mais de seis milhões de cidadãos poloneses, entre os quais três milhões de judeus; na URSS, cerca de um milhão e meio de poloneses foram mortos (em execuções ou por exaustão). Este número abarca $58 \%$ dos advogados, $38 \%$ dos médicos e $28 \%$ dos professores universitários do Pré-guerra. A expatriação e a deportação para a Alemanha e para a URSS, visando trabalhos forçados em campos e em gulags soviéticos, atingiu cerca de cinco milhões e meio de pessoas. Mais de dois milhões de habitantes dos territórios do leste poIonês, ocupados pela URSS, perderam suas casas. Após a guerra, eles foram forçados a estabelecer-se em territórios concedidos à Polônia pelos Aliados em virtude de decisões tomadas em 2 de agosto de 1945, em Potsdam, ou seja, nos departamentos da Alemanha Oriental de antes de 1939. As perdas materiais da economia polonesa ultrapassaram treze vezes o nível do PIB de 1938. As perdas enormes das famílias continuam incalculáveis até hoje ${ }^{4}$. Os alemães e os soviéticos roubaram inúmeros objetos e obras

4 Retracemos o destino típico (sem ser o mais trágico) de uma família polonesa como a de minha mãe, que vivia no vilarejo de Dobrzec perto de Kalisz: em outubro de 1941, na aurora, a Gestapo invadiu sua casa ordenando que eles fizessem suas malas em meia hora e deportou toda a família a $150 \mathrm{~km}$ para o leste. Sua casa foi cedida a colonos alemães. Neste novo lugar, a família de minha mãe ocupou um celeiro abandonado. Meus avós e minha tia, então com treze anos, foram forçados a trabalhar em uma fazenda alemã, confiscada, por sua vez, de proprietários poloneses no outono de 1939. Na primavera de 1945, a família de minha mãe voltou para sua casa que estava sem móveis, sem ferramentas e sem os animais (exceto duas vacas exaustas que não poderiam ter sobrevivido à viagem de mudança para a Alemanha). Os colonos alemães que fugiam do exército soviético levaram tudo com eles. de arte cujo valor material e cultural são inestimáveis. A maioria deles não foram encontrados até hoje.

A nova ordem geopolítica europeia, que foi imposta pelo regime sócio-político ao meu país durante quatro décadas foi, além das perdas enormes, a consequência mais trágica da guerra. A potência totalitária, a URSS, decidia tudo o que acontecia na Polônia, definia o regime político e econômico polonês dentro dos moldes do regime soviético.

Embora a Polônia tenha sido um dos países vencedores da Segunda Guerra Mundial, a vitória teve um gosto amargo: a nação - que, durante a guerra, forneceu aos Aliados mais de quinhentos mil soldados, que lutaram em todas as frentes de batalha, e mais de duzentos mil membros da maior resistência da Europa - não foi autorizada a participar das decisões sobre a nova ordem no continente, tampouco no seu próprio território. Todas as decisões sobre as fronteiras do país no pós-guerra, sua organização étnica, seu regime político e econômico, foram tomadas pelos líderes das três potências mundiais durante as conferências de Yalta (1944) e de Potsdam. Stalin conduzia um jogo de natureza geoestratégico com os chefes de governo da Inglaterra e dos Estados Unidos e tinha todos os benefícios. A política do fato consumado venceu as alianças do pré-guerra: na primavera de 1945, o exército soviético ocupava os territórios que se estendiam dos Balcãs ao rio Elba e à costa báltica da Alemanha. A Polônia tornou-se o espólio de guerra de Stalin.

Consequentemente, cerca de cinquenta mil resistentes poloneses foram mortos ou deportados para o gulag. O referendo sobre o futuro regime político do país, ocorrido em 30 de junho de 1946, foi falsificado; bem como as primeiras eleições legislativas de 19 de janeiro de 1947. Nos anos 19491956, o stalinismo, atrelado ao terror, à denúncia e à exploração econômica da sociedade (com exceção de uma elite no poder), por fim triunfou na Polônia 5 .

5 Os fatos e dados estatísticos, no que diz respeito à Segunda Guerra Mundial e ao Pós-guerra, aqui citados são baseados no livro Historia Polski 1914-1993 de Wojciech Roszkowski (1994). 
Depois de tais eventos e circunstâncias trágicas, o sentimento neurótico de ser uma vítima marcou profundamente a interpretação polonesa da história nacional - de uma nação condenada ao combate eterno pela liberdade, ocupada por seus potentes vizinhos e traída por seus aliados.

Voltemos à nossa tentativa de descrever como o trauma da guerra marcou a arte polonesa, e especialmente o teatro, após a Segunda Guerra Mundial. Sob o regime do terror stalinista, a liberdade de expressão artística tornou-se uma quimera, e a representação do trauma da guerra limitou-se a descrições esparsas dos crimes de Hitler. Deste modo, as proibições impostas pela censura e autocensura juntaram-se às questões universais, tais quais: "Como produzir arte depois de Auschwitz?". No entanto, a literatura polonesa se permitiu duas obras-primas: Medaliony (Medalhões) de Zofia Nalkowska (1946) - uma descrição dos fatos, seca e sem comentários, enfatizando o niilismo e a racionalidade cruel do nazismo e de sua maneira racista de entender a condição humana, e Pożegnanie z Marią (Adeus à Maria) de Tadeusz Borowski (1947) - que relata a trajetória de um sobrevivente de Auschwitz, marcada por uma mordaz auto-ironia, pelo cinismo e pela perda de ilusões no que diz respeito à desumanidade da natureza humana.

Os artistas teatrais poloneses, cujas obras e trabalhos foram censurados e controlados pelo poder comunista, conseguiram criar somente um espetáculo relevante sobre o trauma da guerra antes da subordinação completa do país: trata-se de Electra de Jean Giraudoux, peça apresentada no Palco Poético do Teatro do Exército Polonês em Lodz, em fevereiro de 1946 (encenada por Edmund Wiercinski). O espetáculo, que logrou um grande sucesso de público e de crítica, foi retirado de cartaz em maio de 1946, após quarenta e quatro apresentações. O governo, uma parte da crítica e da classe teatral, influenciadas por este primeiro, acusaram a encenação de enaltecer um misticismo e de glorificar a resistência independentista do período da guerra cujos membros eram chamados, pela propaganda comunista, de "gnomos viscosos e reacionários". Uma análise artística e intelectual honesta e universal do trauma da guerra foi possível no teatro polonês somente após uma ruptura interna do movimento comunista em 1956 (após o "degelo" e o outubro polonês). É preciso também ressaltar que uma descrição escrupulosa das relações polonesa-soviéticas ainda era tabu. O mesmo se deu com os crimes soviéticos da guerra polonesa-soviética de 1920 e o massacre de vinte e dois mil prisioneiros de guerra poloneses pelo NKVD ${ }^{6}$, em 1940. Este último crime foi reconhecido pelo governo russo somente na década de 1990, após a queda da URSS e a independência polonesa. Até então, os soviéticos e o governo comunista polonês, completamente submisso à Moscou, atribuíam esse crime aos alemães, apesar das provas evidentes.

O objeto da minha análise será Akrópolis", memorável espetáculo produzido em 1962, no Teatro Laboratório das 13 Fileiras de Opole ${ }^{8}$, baseado na peça de Stanislaw Wyspianski e com adaptação e direção de Jerzy Grotowski (1933-1999).

6 N.T.: NKVD (sigla em russo para Comissariado Popular de Assuntos Internos) era o então serviço secreto da URSS, instituição precursora da KGB.

7 Akrópolis, a partir da peça de Stanislaw Wyspianski. Adaptação: Jerzy Grotowski. Encenação: Jozef Szajna e Jerzy Grotowski. Assistência de direção: Eugenio Barba. Estreia: 10 outubro de 1962. Teatro Laboratório das 13 Fileiras de Opole.

80 teatro experimental de Opole (Teatr 13 Rzedow - Teatro das 13 Fileiras) foi cedido a Grotowski durante a programação de 1959/60. No verão de 1962, Grotowski mudou o nome da instituição para "Teatro Laboratório das 13 Fileiras". Após a mudança da equipe para Wroclaw (programação de 1965/66), Grotowski passou a denominá-lo como "Teatro Laboratório das 13 Fileiras - Instituto de Pesquisas Teatrais". No início do ano de 1967 o termo "13 Fileiras" foi definitivamente suprimido no nome do Teatro. 
O próprio Jerzy Grotowski conheceu as atrocidades da guerra. Seu irmão, Casimir, cientista eminente, professor de física na Universidade de Jagiellonian (Cracóvia), relatou os infortúnios de sua família ${ }^{9}$ durante a guerra assim:

Em 1939, nós fugíamos dos alemães para o leste. Lembro-me de um piloto alemão que, depois ter nos lançando bombas, disparou contra nós uma rajada de metralhadora. Nossa mãe nos jogou no chão, a mim e ao meu irmão, e nos cobriu com seu corpo. Lembro-me da batida de seu coração. Conseguimos chegar ao nordeste de Lvov. O governo polonês retirou-se e começou o massacre. Os ucranianos assassinaram os poloneses. Mas é preciso ser justo: foi uma ucraniana que nos salvou. Ela fez com que nos deitássemos no chão e não nos movêssemos. No quarto ao lado, havia a família de um policial polonês; eles foram todos degolados. Havia gritos. Em seguida, nos estabelecemos no vilarejo de Nienadowka. Um dia, antes do amanhecer, ouvimos tiros: eram os alemães que sitiavam o vilarejo. Eles iam de casa em casa pegar todos os homens e meninos. Meu irmão e eu estávamos com sarampo, tínhamos crostas no rosto. Um soldado alemão, com uma metralhadora na mão, invadiu nossa casa. Minha mãe the disse que havíamos contraído uma doença contagiosa grave, o soldado não quis nos tocar e se retirou. Eles retiveram todos os dez homens do vilarejo e os metralharam. Todas as noites nos ajoelhamos diante de imagens sagradas e orávamos pelo fim da guerra e pelo retorno de nosso pai. Nosso pai nunca mais voltou para a Polônia depois da guerra. Ele nunca fundou uma nova família. (ZMARZ-KOCZANOWICZ; OSINSKI, 1999).

9 O pai de Jerzy e Casimir, Marian Grotowiski (1898-1968) serviu o exército como voluntário a partir de setembro de 1939 e participou da Campanha da Polônia como oficial do exército. Após a invasão soviética, ele se exilou na Romênia e mais tarde na Hungria, onde ele foi detido. Ele conseguiu fugir do campo de concentração ainda em 1939 e, passando pela Itália e pela França, chegou na Escócia. Uma vez findada a Guerra, tentou trazer sua família para a Escócia. Ele não logrou levar a cabo tal projeto e então mudou-se para a América Latina. Ele faleceu em $1968 \mathrm{em}$ Assunção, capital do Paraguai (OSINSKI, 1993, p. 18-19).
A concepção da encenação de Akrópolis partiu de uma ideia ousada. O encenador polonês se inspirou abertamente nos espetáculos de Vsevolod Meyerhold das décadas de 1920 e 1930. Ele foi influenciado por Meyerhold desde a época de seus estudos em Moscou (1955/1956), onde teve acesso aos arquivos do Instituto Estatal de Arte Teatral (GITIS), um raro privilégio que Ihe permitiu consultar documentos proibidos ao público. Durante as noites, Grotowski estudava o projeto e as descrições dos espetáculos do gênio russo (então considerado espião e inimigo do poder soviético), especialmente os de O Inspetor geral de Gogol (1926) ${ }^{10}$.

A ação de Akrópolis, um drama modernista de Stanislaw Wyspianski, publicado em 1904, se passa na noite de Páscoa na Cracóvia, a antiga capital da Polônia, na catedral do castelo real na colina Wawel. Os anjos animam personagens míticos das esculturas e pinturas, como São Estanislau, patrono da Polônia, e de heróis da mitologia grega ou de histórias bíblicas. Eles evocam os temas e os momentos-chave da história da Polônia e, especialmente, das mitologias grega e judaico-cristã, para culminar no ato IV: ressuscitar e libertar do caixão a águia branca, emblema da Polônia, que anuncia o renascimento nacional e a independência.

As duas palavras-chaves da interpretação de Grotowski do drama, repetidas obstinadamente pelos atores na primeira parte do espetáculo, são: "nossa Acrópole" (é o que o autor da peça chama de Catedral do castelo real de Wawel) e "cemitério das tribos". Wyspianski situou a ação de sua peça sem trama narrativa na "Acrópole polonesa". Os temas mitológicos deveriam constituir, segundo o próprio autor, uma síntese da civilização europeia. Eles também demonstram a ancoragem de Polônia na cultura ocidental e simbolicamente representam o caminho da independência do país, partilhado pelas três potências europeias.

10 As circunstâncias que permitiram a Grotowiski ter acesso aos arquivos da GITIS são descritas por Zbigniew Osinski (2009, p. 293-294). 
Grotowski decidiu abandonar a interpretação "patriótica" do drama de Wyspianski e torná-la universal. Daí vem sua ideia de localizar "nossa Acrópole" no "cemitério das tribos", compreendido metaforicamente como uma soma da civilização europeia, mas também de modo literal: a ação do espetáculo se passa em um campo de concentração (Auschwitz está apenas a $80 \mathrm{~km}$ da Cracóvia, Majdanek a 270 $\mathrm{km})$. Todos os personagens mitológicos eram interpretados pelos prisioneiros do campo. Os atores recitavam os diálogos enfáticos e escritos num estilo bíblico, interpretando cenas da vida no campo de concentração cuja atrocidade e desumanidade faziam parte do cotidiano banal. Se, na obra de Wyspianski, a escultura de uma jovem que tomou vida, maravilhada com seu aspecto humano, diz: "São meus cabelos que brilham no emaranhado de cachos prateados", no espetáculo de Grotowski essas palavras são repetidas por um prisioneiro que está separando os cabelos de pessoas mortas na câmara de gás para que eles possam ser destinados a um uso industrial. Na peça de Wyspianski, os anjos que animam a escultura de uma outra mulher fazem-lhe algumas perguntas e garantem a ela que foram eles quem Ihe deram vida. Na encenação de Grotowski, a cena em questão torna-se um cruel interrogatório de um prisioneiro, conduzido por dois outros encarcerados que se tornaram algozes. Uma vez o interrogatório terminado, a vítima é jogada ao chão e, no final da cena, assassinada e pendurada em um arame. Deste modo, o diálogo: “- Para onde você está me arrastando? - Em direção à luz", é dotado de uma ironia trágica (FINDLAY, 1984).

Em sua introdução ao filme Akrópolis, (filmagem do espetáculo gravado nos estúdios da BBC em 1968), Peter Brook afirma que o espetáculo de Grotowski se aparenta a natureza perigosa de um ritual:

Em Akrópolis [...] o ritmo da vida cotidiana em um campo de concentração é revelado ao público. Eu tinha a impressão de assistir algo horrendo, realmente repulsivo, algo indescritível. Este horror difícil de nomear não se apresentava ao público como um fato do passado, eles se desenvolviam diante de nossos olhos. Todo mundo espera que [...] o que esteja em jogo numa obra de arte seja sua autenticidade. Se consideramos que o campo de concentração é o maior pesadelo de nosso tempo, chegamos à conclusão que a maneira mais justa de o descrever numa obra de arte seria num formato documentário. [...] O único objeto capaz de simbolizar o campo de concentração é o próprio campo de concentração. Com Akrópolis, Grotowski demonstra que existe uma exceção a esta regra. [...] Seus atores revivem e fazem ressurgir por um momento a atmosfera do campo de concentração. Tal situação é mais realista do que os fatos objetivos. [...] A natureza e a essência do campo de concentração se apresentam diante de nossos olhos. Pode-se cheirá-lo, tocá-lo e experimentá-lo. E não se pode dizer que isso nunca mais acontecerá no mundo e que isso não diz mais respeito à humanidade, que isso é apenas um sonho de Hitler - um fato que certamente não podemos esquecer, mas que aconteceu no passado. Está acontecendo aqui e agora - um grupo de artistas volta a torná-lo real. É nesse sentido que a peça se aproxima de um ritual. (GROTOWSKI et al., 1968).

O horror foi acentuado pelo fato dos atores representarem no meio da plateia ${ }^{11}$, encontrando-se por vezes a apenas alguns centímetros do rosto dos espectadores. Com efeito, uma centena de espectadores ocupavam o meio do palco, sentados em cadeiras espalhadas por todo o espaço cênico. Os atores ignoraram a presença do público para pôr em evidencia sua condição de "admitidos" à uma experiência extrema, separados dos espectadores pela fronteira da morte. Eles representavam os mortos que assombravam o mundo do Pós-guerra e se apresentam aos vivos como personagens de um pesadelo.

Os figurinos, concebidos pelo grande diretor e cenógrafo Jozef Szajna, que havido sido prisioneiro de Auschwitz, eram limitados a

11 Contrariamente aos dois espetáculos precedentes do Teatro Laboratório encenados por Grotowski, Dziady, (1961) baseado na peça de Adam Mickiewicz e Kordian (1962) baseado na peça de Juliusz Slowacki. 
sacos furados em corpos nus. Os furos são forrados de camadas coloridas e cortados como se fossem não apenas defeitos dos tecidos, mas também matéria orgânica esfarrapada, a carne corporal dilacerada exposta por dentro. Os atores usam pesados tamancos de madeira e boinas escuras na cabeça - uma versão poética dos uniformes dos prisioneiros do campo de concentração. As indumentárias são idênticas, privando as pessoas de seus aspectos individuais; encobrem quaisquer atributos de status social, gênero ou idade. (FLASZEN, 2015, p. 125).

Os atores atuaram no palco no meio de uma

pilha de sucata: chaminés de fornalhas de vários comprimentos e formas, carrinhos de mão, uma banheira, pregos, martelos. Tudo enferrujado, envelhecido e real [...]. No decorrer da ação, os atores erigirão uma construção feita deste lixo metálico enferrujado - pendurando-os em cordas esticada no teto e ligando-os ao chão em diagonal -, uma operação da absurda 'civilização dos tubos das fornalhas' que gradualmente preencherá a sala inteira. (FLASZEN, 2015. p. 124).

A cena final da Akrópolis de Grotowski e do Teatro Laboratório começava com a fala do Cantor (Zygmunt Molik)

O exaustivo agrupamento conduzido pelo cantor encontra seu Salvador. Quem é esse Salvador? [...] Um cadáver. Um boneco pálido, partido, sem cabeça, que se parece com um magro prisioneiro morto. Com as duas mãos, o cantor ergue essa forma patética num gesto solene, como o padre erguendo o santo cálice. A multidão, num impulso religioso, fixando o olhar nele, segue o líder em fila única. Começam a cantar uma canção, uma melodia natalina de boas-vindas em louvor ao Salvador. O som da canção aumenta, torna-se uivos extáticos, vozes agudas, gemidos e riso histérico. A procissão circula ao redor da grande caixa no meio da sala com os braços estendidos ao Salvador, com os olhos arrebatadoramente focados nele. [...] Finalmente, no auge do êxtase, o grupo chega ao fim de suas andanças. Em meio ao silêncio, o Cantor grita uma prece, abre a tampa da caixa e entra com o manequim Salvador. Cantando histericamente, os outros o seguem, um de cada vez, num transe. Todos os convictos desaparecem no buraco, e a tampa se fecha. Silêncio súbito. Depois de uma pequena pausa, uma voz sóbria de fato é ouvida dentro da caixa: "Eles se foram - e fumaça sobre espiralando." A alegre loucura encontra seu fim no forno crematório. (FLASZEN, 2015. p.127).

A justaposição do drama modernista de Wyspianski, atrelada às ideias universais da cultura ocidental e aos símbolos patrióticos, com a realidade do campo de concentração provocou um profundo choque no público. Os espectadores poloneses estavam familiarizados com a vida no Gulag, ou por suas próprias experiências ou pelo intermédio de histórias de familiares ou amigos. Alimentados igualmente por narrativas de Borowski e Nalkowska e inúmeras adaptações cinematográficas, documentos e testemunhos na mídia, eles foram, no entanto, surpreendidos por uma dissonância entre o conteúdo do texto e seu estilo e o que estava acontecendo no palco. O trauma da guerra, cujos traços dolorosos estavam presentes na sociedade polonesa na década de $1960^{12}$,aumentou ainda mais o choque. Era essencial para que a mensagem de Grotowski e sua companhia fosse completa, baseada na "dialética da apoteose e do escárnio". Essa dialética, pilar da estratégia artística de Grotowski, consistia em desafiar a interpretação tradicional dos mitos nacionais e religiosos, zombar da leitura estereotipada destes últimos e revelar ao público seus reais significados trágicos. Assim, os espectadores foram capazes de relacionar esse significado universal com suas próprias vidas, para se perguntar sobre o significado profundo e verdadeiro de sua existência.

O trauma da guerra que Grotowski compartilhou com muitos espectadores de Akrópolis (não apenas na Polônia, mas também no exterior, em pa-

12 Vale lembrar que os documentos oficiais mencionavam somente os crimes nazistas, omitindo o genocídio soviético cujas denuncias eram feitas por programas radiofônicos em polonês (mas transmitidos somente na Europa ocidental, como Rádio Free Europa, Rádio France Internationale, Deutshe Welle, $B B C$, etc.) e por revistas e livros em polonês editados no exterior e trazidos clandestinamente para a Polônia. 
íses onde o espetáculo foi apresentado) foi evocado de uma nova maneira durante esse "ritual" no teatro. Confrontado com os mitos universais da cultura ocidental, a inconcebível desumanidade da realidade do campo foi revelada no espetáculo de Grotowski em toda a sua evidência, acompanhada do horror. Peter Brook dizia que a maioria dos espectadores de Akrópolis "sai do teatro em silêncio. Eles viram com seus próprios olhos o que prefeririam somente ter escutado falar. [...] Somente um pequeno grupo de espectadores pode enfrentar essa experiência" (GROTOWSKI et al., 1968). Cabe a consciência dos espectadores decidir se Auschwitz é uma "nova Acrópole" do mundo pós-guerra ou não; e eles podem também ser capazes de não permitir que o drama que eles acabaram de testemunhar aconteça novamente em algum outro lugar "entre o gênero humano".

\section{Referências}

FINDLAY, Robert. "Grotowski's Akropolis: A Retrospective View”. In: Modern Drama, n²7, março de 1984 , p. 6-10.

FLASZEN, Ludwik. "Dziady, Kordian, Akrópolis no Teatro das 13 Fileiras". In: FLASZEN, Ludwik. Grotowski e Companhia, Origens e Legados. [Tradução de Isa Etel Kopelman]. São Paulo: Editore É Realizações, 2015, p. 109-130.

GROTOWSKI, Jerzy [encenação]; BROOK, Peter [comentário e apresentação]; MACTAGGART, James [filmagem]; FREEDMAN, Lewis [produção]. Akropolis. Reino-Unido: Insight Media, 1968, 76min.

OSINSKI Zbigniew. "Pierwsza inicjacja Jerzego Grotowskiego". In: OSINSKI Zbigniew, Grotowski wytycza trasy. Varsóvia: Ed. Pusty Oblok, 1993.

OSINSKI Zbigniew. "Grotowskiego doświadczenie Rosji”. In: Pamietnik Teatralny 2009, 1 - 4 (193-196), p. 293-294.
ROSZKOWSKI, Wojciech. Historia Polski 1914-1993. Varsóvia: Wydawnictwo Naukowe PWN, 1994.

ZMARZ-KOCZANOWICZ, Maria [direção]; OSINSKI, Zbigniew [roteiro]. Jerzy Grotowski, proba portretu (Jerzy Grotowski, un coup de portrait), Polônia/ França, filme coproduzido por Telewizja Polska S.A. e Arte, 1999, 58min.

Recebido: 17/02/2021

Aceito: $17 / 02 / 2021$

Aprovado para publicação: 13/04/2021

Este é um artigo de acesso aberto distribuído sob os termos de uma Licença Crea- tive Commons Atribuição 4.0 Internacional. Disponível em: <http://creativecommons.org/licenses/by/4.0>.

This is an open-access article distributed under the terms of the Creative Commons Attribution License 4.0 International. Available at: <http://creativecommons.org/licenses/by/4.0>.

Ce texte en libre accès est placé sous licence Creative Commons Attribution 4.0 International. Disponible sur: <http://creativecommons.org/licenses/by/4.0>. na Segunda Metade do Século XX: o exemplo do espetáculo Akrópolis do Teatro Laboratório das 13 Fileiras encenado por Jerzy Grotowski Revista Cena, Porto Alegre, n 33 p. 48-56 jan./abril 2021 Disponível em: http://seer.ufrgs.br/cena 